\title{
Canadian astronomers mount lobby effort
}

Steve Nadis

Tired of meagre grant support and alarmed at their possible exclusion from international projects, Canadian astronomers are mounting an aggressive lobbying campaign to win more financial support.

Canadian astronomy is rated third in the world in terms of citations per paper, despite, Canadian astronomers claim, the government spending seven times less per head than the United States.

But Canadian astronomers say they will be unable to maintain their position without a significant financial boost. "The rules of the game have changed," says University of Calgary astronomer Russ Taylor, president of the Canadian Astronomical Society. "Astronomy is becoming more international and the stakes are getting bigger." More resources are needed, he says, for his country to participate in the observatories of the future.

The Coalition for Canadian Astronomy, which is made up of academics and industrialists, has been formed to persuade the government to increase funding. "A campaign of this kind, which puts all astronomy under a single umbrella, is a first for us," says Ralph Pudritz, an astronomer at McMaster University, Ontario, who serves on the coalition's executive committee. "We're slowly catching on to the American way of doing things."
Pudritz chaired a national panel that authored a report, published last summer, which set priorities for Canadian astronomy over the next decade. The coalition wants to implement this plan. "We're making the case as an entire community, rather than vying for support for individual projects as we've done in the past," Pudritz says.

The coalition is calling for Can $\$ 16.4$ million (US\$10.9 million) per year over the next ten years for ground-based astronomy; about twice the current funding. The top priority will be involvement in the Atacama Large Millimeter Array (ALMA) in Chile, destined to become the world's most powerful radio telescope in millimetre and submillimetre wavelengths.

Last month, Canada's National Research Council and the US National Science Foundation reached an agreement to give Canadian astronomers access to ALMA and all major US radio observatories.

Researchers also aim to contribute to the designs of the Square Kilometre Array, a centimetre-wavelength radio telescope, and the Very Large Optical Array.

The coalition is seeking Can\$75 million over ten years to allow participation in NASA's Next Generation Space Telescope and another Can\$25 million for the European Space Agency's Planck mission

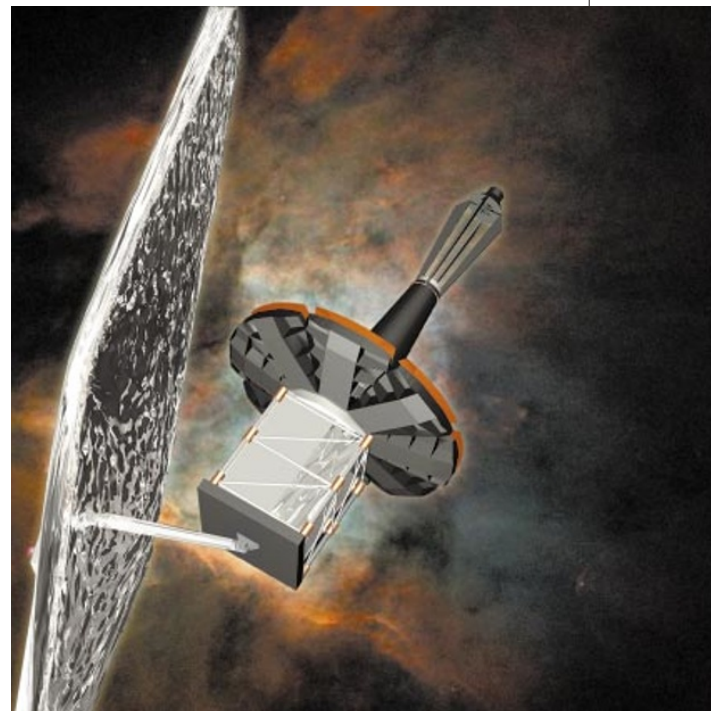

High hopes: Canadian astronomers hope to join the Next Generation Space Telescope project.

to study cosmic background radiation.

Taylor and other coalition members were in Ottawa this week, lobbying members of parliament. "This is make or break for us," says Pudritz. "If we're not part of the world observatories, recruitment efforts will suffer and we'll lose our edge within a decade."

\section{Scientists unimpressed by Australia's funding plan}

Peter Pockley, Sydney

Australian scientists have reacted ambivalently to the conservative government's plan to inject new funding into research.

A dozen programmes would be started or expanded under a plan released late last year by Robin Batterham, the government's chief scientist. He proposes adding A $\$ 1.8$ billion (US\$1 billion) to government spending over five years, most of it for university-based research.

The largest expansion would be a doubling of grants through the Australian Research Council, costing A \$660 million, a

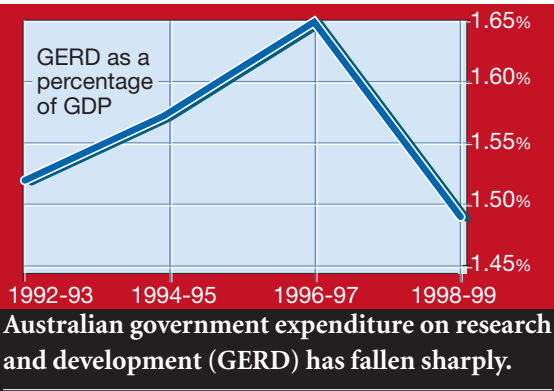

NATURE|VOL 409|11 JANUARY 2001| www.nature.com
A \$150 million expansion of the Cooperative Research Centres, and A $\$ 400$ million of extra funds for major new research facilities.

The plan would try to leverage more industrial research, which has been in decline in Australia. Batterham says the country's competitive position has been "reasonable" in the past, but admits that it must now be improved. "Finland and Ireland over ten years have more than doubled their business investment" in research and development, he says. "We haven't ... the case presented is too powerful to ignore."

The government is expected to respond to Batterham's proposal in a statement on innovation to be issued early this year. Although universities and research bodies are urging the government to implement Batterham's plan in full, they are separately calling for larger boosts in general support to restore Australia's investment to previous levels (see chart, left).

Barry Osmond, a plant biologist who is leaving Australia to head Columbia University's Biosphere 2 facility in Arizona (see Nature 408, 396; 2000), is unimpressed by the plan. Australian science "had a

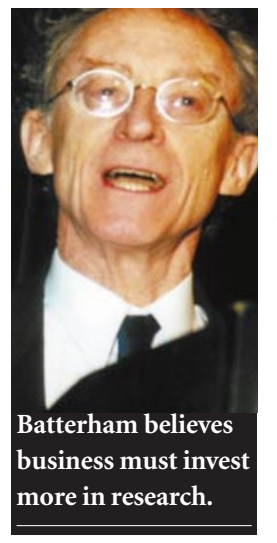

tremendous reputation", he laments.

"Government or the bureaucracy have just let science run down to the point where it's on the verge of irredeemable damage. The current proposals are peanuts. It needs billions of dollars per year. Compared to our competitors in this field, we're doing nothing," Osmond says.

An analysis by Australia's top eight research universities says it would take A\$9.4 billion over five years to raise the country's research spending to the developed world's average of just over $2 \%$ of gross domestic product (GDP).

Since the middle of last year, the plight of Australian science has attracted considerable media coverage, putting pressure on the government to support it as it enters an election year. 